\title{
Lemke, Michael, Vor der Mauer. Berlin in der Ost-West Konkurrenz 1948 bis 1961
}

Élise Julien

\section{(2) OpenEdition}

Journals

Édition électronique

URL : http://journals.openedition.org/ifha/6542

DOI : 10.4000/ifha.6542

ISSN : 2198-8943

Éditeur

IFRA - Institut franco-allemand (sciences historiques et sociales)

Référence électronique

Élise Julien, «Lemke, Michael, Vor der Mauer. Berlin in der Ost-West Konkurrenz 1948 bis 1967 ", Revue de I'IFHA [En ligne], Date de recension, mis en ligne le 01 janvier 2012, consulté le 22 septembre 2020. URL : http://journals.openedition.org/ifha/6542 ; DOI : https://doi.org/10.4000/ifha.6542

Ce document a été généré automatiquement le 22 septembre 2020

(CIFHA 


\title{
Lemke, Michael, Vor der Mauer. Berlin in der Ost-West Konkurrenz 1948 bis
} 1961

\author{
Élise Julien
}

1 À l'occasion du 50e anniversaire de la construction du mur de Berlin en 2011, on s'est de nouveau interrogé sur sa signification : s'agissait-il d'une prodigieuse démonstration de force ou au contraire d'un signe d'impuissance? Si ses instigateurs revendiquaient la nécessité d'une protection antifasciste pour couper physiquement la ville en deux, on a souvent considéré que ce mur matérialisait finalement une division politique, économique, sociale et culturelle qui préexistait dans la vie des Berlinois depuis plus d'une décennie.

2 C'est à la période d'« avant le mur » que s'intéresse ici M.L., historien du Zentrum für Zeithistorische Forschung de Potsdam. Le propre de cet ouvrage est de tenter de sortir de l'historiographie classique du Berlin contemporain, largement issue de la Guerre froide, dont les travaux se concentrent sur la construction idéologique et pragmatique des blocs et qui a tendance à en entretenir l'esprit. Il ne s'agit pas ici d'ignorer la concurrence entre deux systèmes - l'un capitaliste et l'autre socialiste -, mais de la dépasser pour initier une étude globale de Berlin, prenant en compte les interactions locales et les formes diverses de circulation et de coopération qui se développent dans l'espace berlinois.

3 L'auteur procède pour cela à une analyse systématique. Dans la première partie, il s'occupe de politique au sens classique : il fournit en quelque sorte le cadre d'une recherche qui descend ensuite dans le quotidien des Berlinois, pour se concentrer sur les passeurs de frontières, ceux qui incarnent les relations entre les différents secteurs de la ville. La deuxième partie porte en effet sur les aspects économiques et sociaux. Elle permet de montrer que jusqu'en 1961, Berlin-Est et Berlin-Ouest se trouvent en étroite relation, aussi bien à cause des déplacements de travail que des pratiques de consommation : au début des années 1950, les Berlinois de l'Ouest réalisent 50 à $60 \%$ de leurs achats à l'Est où les denrées sont moins chères, tandis que les Berlinois de l'Est 
vont chercher à l'Ouest les produits ou la qualité qu'ils ne trouvent pas à l'Est. La troisième partie porte enfin sur les concurrences et les imbrications culturelles. Dans ce domaine, Berlin-Est dispose d'un avantage au milieu des années 1950. Mais l'auteur souligne le rôle joué ensuite par le " plan culturel pour l'ensemble de Berlin " (Gesamtberliner Kulturplan), impulsé par le maire de Berlin-Ouest Willy Brandt en 1957 et subventionné par la RFA. Ce plan favorise le développement de l'offre culturelle afin de mieux symboliser l'attractivité occidentale, de même qu'il prévoit de faciliter l'accès des Berlinois de l'Est aux spectacles et manifestations culturelles de l'Ouest par des tarifs paritaires entre les deux marks. Si cette offensive culturelle de Berlin-Ouest s'insère clairement dans le contexte de la Guerre froide, provoquant une réplique rapide des autorités de Berlin-Est, son succès contribue dans le même temps au maintien d'une certaine communauté culturelle dans la ville divisée.

Alors que Berlin concentre de manière inédite la concurrence et la confrontation de deux systèmes, cet exemple parmi bien d'autres vient montrer que celles-ci ont des effets équivoques : elles peuvent renforcer la division entre les différentes parties de la ville autant que leur imbrication. L'auteur montre en outre que la population locale développe rapidement une relative indifférence aux crises politiques internationales, un sentiment qu'il désigne comme celui d'une "normalité de la Guerre froide » et qui contribue à une certaine identité globale de la ville. Berlin reste perçu par ses habitants comme une entité unique et comme le territoire d'une appartenance commune, grâce notamment à la porosité de ses frontières intérieures. Or les relations intra-berlinoises sont un facteur important du choix « séparatiste » effectué par la SED en faveur de la construction du mur : l'effet « vitrine » tourne progressivement à l'avantage de BerlinOuest, ce qui rend le succès de la propagande orientale d'autant plus problématique que la RDA est confrontée à une fuite de ses habitants et à des difficultés économiques croissantes.

Il s'agit là pour finir d'un ouvrage très documenté, qui s'appuie sur de nombreuses sources d'archive, articles de presse, récits de témoins, et qui reproduit dans un carnet central un grand nombre de photos en noir et blanc, largement issues des fonds du Landesarchiv Berlin et pour une bonne part inédites. L'auteur aurait néanmoins pu lister ses sources dans le détail : il aurait ainsi facilité la tâche de ses potentiels continuateurs. Il faut en effet souhaiter que ceux-ci soient nombreux, tant ce volume est un jalon important sur la voie d'une histoire de la société berlinoise pendant la Guerre froide.

Élise Julien (IEP Lille) 